\title{
PEDAGOGICAL CONDITIONS FOR THE DEVELOPMENT OF COGNITIVE INDEPENDENCE FOR HUMANITARIAN STUDIES IN THE PROCESS OF MATHEMATICAL EDUCATION
}

\author{
Augustina Vasilievna Ivanova ${ }^{1}$ \\ Alexei Innokentievich Golikov ${ }^{2}$ \\ Alevtina Gavrilovna Skryabina ${ }^{3}$ \\ Irina Vasilievna Gogoleva ${ }^{4}$ \\ Laura Agitovna Darbasova ${ }^{5}$
}

\begin{abstract}
The relevance of this study is determined by the modern requirements related to both the structure of the learning process and the results of training and educating the younger generation in the context of globalization and informatization of a rapidly
\end{abstract}

changing society. This manuscript is focused on discussing the development of cognitive independence, through humanities classes, among students studying mathematics at a basic level of the new federal state educational standard. The purpose is to find

1 Doctor of Pedagogical Sciences, Professor, Department of Primary Education, Pedagogical Institute, Ammosov North-Eastern Federal University, Yakutsk, Russian Federation; 677000, Russian Federation, Republic of Sakha (Yakutia), Yakutsk, 2 Lenin Ave., Ivaya1@bk.ru, orcid: 0000-0003-4182-4228, AuthorID: 329578.

2 Doctor of Pedagogical Sciences, Professor, Ammosov North-Eastern Federal University, Yakutsk, Russian Federation; 677000, Russian Federation, Republic of Sakha (Yakutia), 58 Belinsky Str., orcid: 0000-0003-4112-4045, AuthorID:299049.

${ }^{3}$ Candidate of Pedagogical Sciences, Senior Lecturer, Department of Methods of Teaching Mathematics, Institute of Mathematics and Informatics, Ammosov NorthEastern Federal University, Yakutsk, Russian Federation; 677013, Russian Federation, Republic of Sakha (Yakutia), Yakutsk, 48 Kulakovsky Str., orcid 0000-0001-9743-2122 ${ }^{4}$ Candidate of Pedagogical Sciences, Associate Professor of Applied Mechanics, Faculty of Engineering, Yakutsk State Agricultural Academy, Yakutsk, Russian Federation; 677007, Russian Federation, Republic of Sakha (Yakutia), Yakutsk, 3rd km. Sergelyakhskoe highway, bld. 3, orcid: 0000-0001-8120-4889, AuthorID:298761.

${ }^{5}$ Candidate of Pedagogical Sciences, Associate Professor of the Department of Applied Mechanics, Faculty of Engineering, Yakutsk State Agricultural Academy, Yakutsk, Russian Federation; 677007, Russian Federation, Republic of Sakha (Yakutia), Yakutsk, 3rd km. Sergelyakhskoe highway, bld. 3, orcid: 0000-0001-5621-2780, AuthorID: 566145 
pedagogical conditions that contribute to the development of the cognitive independence of students in humanities while studying mathematics at a basic level. The authors provide a logical and didactic analysis of the existing basiclevel mathematics textbooks and describe the features of the students in the humanitarian classes. The authors substantiate the pedagogical conditions required for the development of cognitive independence among these students: enrichment of the content of the humanitarian subject areas with an educational and methodological complex aimed at developing cognitive independence; the involvement of students in the humanitarian classes to develop an independent cognitive process under the condition of using the educational information environment. These conditions are said to activate mental activity, contributing to the development of cognitive independence in the study of mathematics. The authors describe pedagogical approaches (activity-oriented, personality-oriented, information-communicative, and competency-based approaches) that contribute to the development of students' cognitive independence. The
668

authors present the research methods (assessment of motivation for learning activities, observation of the manifestation of students' strength-will during tasks, the quality of knowledge in mathematics). The authors conducted an experiment on the implementation of sound pedagogical conditions, the results of which are described in this manuscript. The introduction of the proposed pedagogical conditions into the educational process is of practical importance and is expected to contribute to the effective development of cognitive independence, through humanitarian classes, among students studying mathematics.

Keywords: independence, cognitive activity, students, pedagogical conditions, approaches.

\section{Introduction}

In the documents on the introduction and implementation of Federal State Education Standards (FSES) of secondary general education, considerable attention is paid to improving the quality of subject knowledge, the formation of universal educational activities, and research skills. Thus, V. S. Avanesov (2017) 
states that "it is necessary to create own educational process, suitable for each student, according to its development path, with own estimates of the growth of educational achievements" (Avanesov, 2017).

According to E. A. Sedova (2015), over the past decades, the actual content of school mathematics has become more saturated due to the introduction of new sections and, at the same time, more abstract. The problem of developing the cognitive independence of students in the study of mathematics at a basic level requires special attention since there are more students of mathematics at this level (future philologists, lawyers, historians, artists, athletes, etc.) than students in the natural sciences. V. N. Klepikov (2017) finds that at present, most modern schoolchildren have a clip way of thinking, and when studying mathematics, he offers a method of plastic modeling and interpretation of texts. Students of the humanitarian classes, in virtue of their physiological characteristics, need a different approach to the study of mathematics. They have mostly visual-figurative thinking, their visual perception is well developed, their imaginative memory predominates, their generalization ability is less developed, their arbitrary memorization is poorly developed, and their personal qualities include those that make them dreamers, visionaries, quick-witted, curious, and sociable, among others.

At the present stage, in the process of teaching mathematics, the parallel development of the cognitive independence of students becomes necessary. However, to date, as shown by the analysis of mathematics textbooks, a survey, and the conversation with teachers and students, the constraining factor in the formation of cognitive independence in mathematical education is insufficient consideration of the characteristics of students in humanitarian classes; the task material in the textbooks does not arouse interest in the subject and does not meet the needs and capabilities of students in humanitarian classes.

The process of developing cognitive independence in high school students is entirely dependent on both the student and the teacher's actions; it is a form of self-realization and selforganization of the student and the teacher's effort in organizing the students' 
cognitive activity. Therefore, it is necessary to create pedagogical conditions for the development of the cognitive independence of students in humanitarian classes in the study of mathematics. During the study, the following tasks were solved: Conversations with teachers of mathematics and a survey of students in humanitarian classes were held; textbooks and didactic materials in mathematics intended for teaching at a basic level were analyzed; pedagogical conditions aimed to help develop the cognitive independence of students of humanitarian classes were substantiated.

\section{Literature Review}

Recognizing the work of domestic teachers and psychologists, whose studies note that the independence and creative activity of students develop most intensively in the process of their independent cognitive activity and in the development of their thinking and abilities, the authors especially consider the work of modern researchers O.V. Petunin (Petunin, 2016) and V.N. Pustovoitov (Pustovoitov, 2010).

The involvement of students in the study of mathematics and the problems of mathematical education abroad are addressed in the research by Amy Roth McDuffie (McDuffie, 2018), Carolyn A. Maher (Maher, 2018), Doug Clarke (Clarke, 2018), Fou-Lai Lin (Lin, 2018) and others. The problem of the development of cognitive activity and the influence of students' physical activity in mathematics classes have been extensively represented abroad by researchers such as Jozef Simuth (Simuth, 2015) and Katherine B. Owen (Owen, 2018). The introduction of digital technologies in the educational process and its problems and prospects have been extensively explored by E. A. Barakhsanova, V. M. Savvinov, E. Z. Vlasova, M. S. Prokopyev, I. V. Gosudarev et al. (Barakhsanova, 2016). The study of mass communication in the young generation in the information society and the impact of information and communication technologies on students can be found in the works by E.A. Barakhsanova, I.I. Mulgarov, et al. (Mulgarov, 2016). R.A. Yafizova, A.D. Nikolaeva, and Yu.A. Koshevarova, et al., show the implementation of interactive teaching methods in the educational process in the works (Yafizova, 2016). 
When talking about the development of the cognitive independence of students in the humanities classes in the study of mathematics, it comes to creating conditions, based on the characteristics of students with a humanitarian mindset and justification of these pedagogical conditions.

At present, modern education is focused on a personality-oriented approach, providing individual learning, considering their capabilities and needs. In these conditions, independent work becomes one of the priority means of training and education; it forms such a personality quality as independence, which is expressed in the ability to set certain goals and objectives, to achieve their achievement on their own without outside help (Rohaeti, 2019).

Therefore, while working on the development of students' cognitive independence, the teacher should create favorable conditions for maintaining curiosity; supplement it with new motives that go from the content of training, forms and methods of organizing cognitive activity, from the style of communication with students and the students themselves. The teacher
671

should adhere to the following provision: whether the student realizes the need for teaching; seeks to deepen the knowledge gained; what are the student's interests steady, fleeting; can cope with their unwanted motives, etc.

A motive is a human's impulse to action. The main task of a teacher is to educate the motivation of learning (Markova, 2017).

Considering the above arguments, the compilation of an educational and methodological complex aimed at developing cognitive independence, considering the peculiarities of humanities, is being updated. A training package is a set of systematic educational materials designed to ensure the organizational and substantial integrity of the system, methods, training tools aimed at the formation and development of students' cognitive, creative activities, etc.

The selection of school content is the most important step in creating a learning model. The most significant and relevant of them were identified by L.A. Krasnova, in high school to pay attention to the following direction in the selection of the content of mathematical education: firstly, considering the key 
trends and factors of modern reality, acting as a sociocultural basis for highlighting content elements; secondly, a set of principles defining the methodological basis for the selection of elements of the content of education. Moreover, in this regard, the authors note that humanitarian education is reserved in the methodological basis for the selection of elements of the content of education among the totality of principles (Krasnova, 2017).

The task material for students must meet the following requirements: firstly, it should be interesting, fascinating, entertaining and cause a desire to solve a problem; secondly, it should consider individual characteristics, meet the needs and capabilities of students (Rakhmatullina, 2015). This implies compliance with the variability in the selection of tasks.

Therefore, as the first pedagogical condition, the authors will consider the enrichment of the content of the subject areas of the curriculum of the humanitarian classes with an educational and methodological complex aimed at developing cognitive independence.

In substantiating the second pedagogical condition for the development of cognitive independence of students in the humanitarian classes, the authors will proceed from the activity-based nature of cognitive independence and the characteristics of students in the humanitarian classes. Based on the priority of visual-figurative thinking, visual memory, emotional perception of students in the humanitarian classes, it seems appropriate to involve them in a cognitive independent process in the conditions of using the information educational environment.

The creation of an information and educational environment, considering the specific needs of students in the humanitarian classes, contributes to the independent acquisition of knowledge and the qualitative assimilation of information, automation of the processing of learning outcomes and progress in learning. The use of the Internet and the technologies based on its use in the educational process is a powerful means of introducing interactive teaching methods. In the organization of any educational process, the advantages of using information technology tools increase, in this case, the teacher ceases 
to be a living source of knowledge, which becomes a creator of resources, a companion, an inspirer of students' independent activities (Laptev, 2016).

Below, the authors provide didactic opportunities for the use of information technology (IT) in the educational process for the following purposes: expansion of the educational environment; assistance in the research process, results measurement, and computer simulation of the studied subjects; automation of computing activities; automation of information retrieval activities for the collection, accumulation, storage, processing, and transmission of information; computer visualization of educational information; formation and improvement of skills; consolidation of knowledge; assimilation control; and generalization (Ziyautdinova, 2015; Laptev, 2016).

The use of IT tools in lessons and for the creation of an informational and educational environment is necessary but insufficient for the development of students' cognitive independence in humanitarian classes. The authors assert that, given the psychophysiological characteristics of students in humanities classes, the development of cognitive independence is possible only if teachers implement interactive learning using IT tools in the educational process. Interactive learning technology involves active and close communication about all subjects that are used in the pedagogical process. The use of project-based learning technology, web-quest technologies, research technologies, developmental learning technology, problem-solving skills, and differentiated learning can most efficiently facilitate students' involvement in an independent cognitive process.

When instructors use IT tools to enhance the educational process, students can learn how to analyze information, process data, model problems, design objects, and visualize numerical data. Under this assumption, the authors formulate a second pedagogical condition for the development of cognitive independence in humanities classes: the involvement of students in an independent cognitive process using the educational information environment.

The implementation of an activity-oriented, personality-oriented, information-communicative, and 
competency-based approach to teaching is the fundamental factor that influences the development of cognitive independence for students in humanities classes. This active approach, which is tailored to the student's personality, becomes the foundation for project activities in problem-based learning. Notably, the technology used in the interactive teaching method for integrated learning must be closely related to the personality of the student. Personality-based learning fulfills a social role by facilitating communication with other people, providing useful activity, and developing each student's personal plan for learning; thus, it uses the social environment, which is the main source of development of the student's personality, to foster cognitive independence.

A personality-oriented approach considers the student's psychophysiological characteristics, adhering to a differentiated, individual approach in the pedagogical process. The main objective of this technology is to coordinate training and learning (the main sources of cognition); this dynamic relationship should be provided by educational technology that make cognition personally meaningful, emotionally rich, and aimed at satisfying the cognitive needs and interests of each person, regardless of their abilities and educational achievements. In this approach, partnerships arise between the teacher and the student, a respectful attitude to each student and acceptance of them, as they are (Isakhanova, 2017).

One of the most effective pedagogical approaches in the development of cognitive independence of students is the information and communication approach. Modern researchers, such as V.P. Bespalko, V.V. Mironov, V.V. Laptev, M.S. Nikolaev, and others, propose the use in the educational process of information and communication technology tools that effectively ensure individualization, differentiation of education, the formation of independent activity, the development of interest, the effectiveness of the educational process, etc.

Modern education cannot be imagined without a competency-based approach. A.K. Markova, S.I. Osipova, et al. contributed a lot to the development of the competency-based approach. The competency-based approach in 
education is oriented in the formation of universal educational actions in students of a comprehensive school, i.e. the use of acquired knowledge and skills in various situations. The context of such an approach helps to amend the content of education, to provide the use of new forms and technologies of training and wider opportunities for students to develop the ability to self-education and self-development, and to use the acquired knowledge in practice (Osipova, 2017).

Summarizing what has been said above in the aspect of a theoretical study of the development of cognitive independence of students in the humanitarian classes, with the justification of pedagogical conditions based on activity, personality-oriented, information-communicative, and competency-based approaches, based on the age, individual characteristics of the students in humanitarian classes, the authors come to the following conclusions:

- Pedagogical conditions are substantiated, which hypothetically will contribute to the development of cognitive independence of students in the humanitarian classes of high school:
1) enrichment of the content in the subject areas of the curriculum for the humanitarian classes of high school with an educational and methodological complex aimed at developing cognitive independence; 2) the involvement of students in the humanitarian classes in a cognitive independent process in the conditions of using the educational information environment;

- The need to use a polyparadigm approach is substantiated, including the systemic unity of activity, personality-oriented, informationcommunicative and competency-based approaches in learning, focused on the development of cognitive independence of students.

\section{Materials and methods}

The methodological basis of the study is the activity, personalityoriented, information-communicative and competency-based approaches in the study of mathematics by students in the humanities, using modern educational technologies. The authors used theoretical and empirical methods (observing students in the study of mathematics, interviewing students and talking with teachers of mathematics), as 
well as a pedagogical experiment. Rural schools were chosen for this study: Khatystyrskaya Primary and Secondary General School, Aldan region; Momskaya Secondary General School, Momsky district; and Beidiginskaya Secondary General School, Ust-Aldan district, with 68 students participating. These schools were chosen because they are far from the center so there is limited or no internet access, which is the most powerful means of obtaining instant, necessary information for teaching. Instead the teachers use mainly textbooks and additional literature.

The purpose of this study was to investigate the development of cognitive independence in students in the humanities classes in the study of mathematics. The following components were selected as indicators of the formation of independent cognitive activity: motivation for educational activities; the manifestation of willpower when achieving a goal; and the quality of mastering the subject. The following methods were used to identify these components: assessment of motivation for learning activities, monitoring the manifestation of the willpower of students in the performance of tasks and the quality of mathematics knowledge; and the analysis of the results obtained.

The authors used the diagnostic methodology for educational motivation of students proposed by N.P. Fetiskin, V.V. Kozlov and G.M. Manuylov (Fetiskin, N.P., 2002) They proposed a questionnaire consisting of 21 statements. For each of the seven components of motivation there are three corresponding statements. The respondent rates each of the answers on a 4-point scale: 0 for "almost irrelevant", 1 point for "partially relevant", 2 points for "noticeably relevant", 3 points for "very relevant". The components of motivation are as follows: 1) cognitive; 2) communicative; 3) emotional; 4) selfdevelopment; 5) the position of the student; 6) achievements; 7) external (rewards, punishments).

To identify the manifestation of the students' willpower when performing certain activities, the observational method to evaluate volitional qualities developed by A.I. Vysotsky was used (Istratova, 2010). Signs of willpower are: 1) independence; 2) perseverance; 3) exposure; 4) organization; 5) initiative.

Verification and control work in mathematics was carried out to verify the 
quality of assimilation of material in mathematics and to identify the quality of knowledge in mathematics.

\section{Results}

The experiment was conducted from 2016 to 2018 for students in the 10th and 11th grades. In the 10th grade (academic year 2016-2017), the work was carried out to identify the level of development of the cognitive independence of students in the study of mathematics. For this control tests in mathematics and the diagnostic measures to identify motivation and willpower of students were presented, and pedagogical conditions were created. At the end of the experiment, in the 11th grade (academic year 20172018), control diagnostics were carried out. The results on the indicators of the development of cognitive independence are provided in the tables below.

The results of the ascertaining and control stages for identifying educational motivation are shown in Table 1.

Table 1 - The results of educational motivation at the beginning and end of the experiment, in percentage

\begin{tabular}{|c|c|c|c|c|c|c|c|c|c|c|c|c|}
\hline \multirow{2}{*}{ 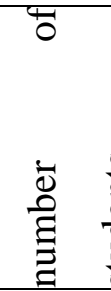 } & \multicolumn{11}{|c|}{ Components of educational motivation } & \multirow[b]{2}{*}{ 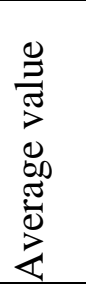 } \\
\hline & $\begin{array}{l}\stackrel{0}{\Xi} \\
: \\
0 \\
0 \\
0\end{array}$ & 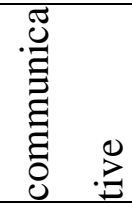 & $\begin{array}{l}\widetilde{\Xi} \\
\stackrel{0}{0} \\
0 \\
0 \\
0\end{array}$ & 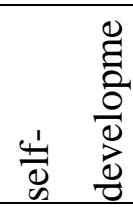 & 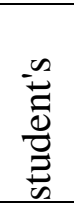 & 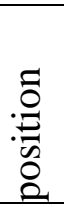 & 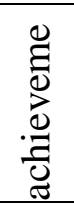 & 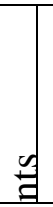 & 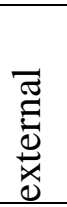 & 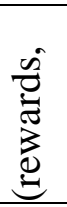 & 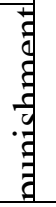 & \\
\hline \multicolumn{13}{|c|}{ the beginning of the experiment } \\
\hline 68 & 57.4 & 67.6 & 44.1 & 60.3 & 71 & & 64.7 & & 53 & & & 59.7 \\
\hline \multicolumn{13}{|c|}{ the end of the experiment } \\
\hline 68 & 82.3 & 76.5 & 54.4 & 73.5 & 79.4 & & 76.5 & & 55.9 & & & 71.2 \\
\hline
\end{tabular}

In regard to the assessment of students' motivation, over $85 \%$ corresponds to the optimal level, 65\%-
$84 \%$ to a sufficient level, and $40 \%-64 \%$ to a low level. As illustrated in the table, at the beginning of the experiment, 
students demonstrated low motivation for educational activity (59.7\%), and educational motivation increased by the end of the experiment corresponding to $71.2 \%$.

The manifestation of the students' willpower was revealed by observation over a two-year period. At the beginning of the experiment, of the selected components of willpower, the smallest indicator was the independent activity (32.3\%) of students, which is an indicator of lack of interest and motivation in the study of mathematics; $39.7 \%$ showed weak initiative (i.e., the authors did not attempt to identify a rational solution to approach the problem creatively, etc. They were not particularly persistent (persistence was
$41.2 \%$ ) in achieving the goal, e.g., they could leave the problem unsolved due to a lack of understanding of the conditions of the problem or because of cumbersome calculations, among other reasons.

By the end of the experiment, the general indicator of the manifestation of willpower among students had increased by $13.9 \%$, i.e., if the number of high school students showing strongwilled qualities for achieving the goal at the beginning of the experiment was 29 , then by the end of the experiment the number was 38 .

The results of the diagnostic data on the strength of the willpower of students are presented in Table 2.

Table 2 - The results of the diagnosis of the strength-will of students in the implementation of actions, in percentage

\begin{tabular}{|c|c|c|c|c|c|c|}
\hline \multirow{2}{*}{$\begin{array}{l}\text { number } \\
\text { of } \\
\text { student } \\
\text { s }\end{array}$} & \multicolumn{5}{|c|}{ will-power components } & \multirow{2}{*}{$\begin{array}{l}\text { averag } \\
\text { e value }\end{array}$} \\
\hline & $\begin{array}{l}\text { independenc } \\
\mathrm{e}\end{array}$ & $\begin{array}{l}\text { perseveranc } \\
\mathrm{e}\end{array}$ & $\begin{array}{l}\text { exposur } \\
\text { e }\end{array}$ & $\begin{array}{l}\text { organizatio } \\
\mathrm{n}\end{array}$ & $\begin{array}{l}\text { initiativ } \\
\mathrm{e}\end{array}$ & \\
\hline \multicolumn{7}{|c|}{ the beginning of the experiment } \\
\hline 68 & 32.3 & 41.2 & 51.47 & 48.5 & 39.7 & 42.6 \\
\hline \multicolumn{7}{|c|}{ the end of the experiment } \\
\hline 68 & 55.9 & 54.4 & 63.2 & 57.6 & 51.5 & 56.5 \\
\hline
\end{tabular}


The quality of knowledge in mathematics was evaluated using the control work proposed at the beginning and end of the experiment; the results are shown in Table 3. The results of the survey and observations at an ascertaining stage testified to the need to use new approaches, means, and technologies of instruction in the mathematics lessons for the formation of independent cognitive activity of students.

Table 3 - Summarized data of the verification work in schools at the beginning and end of the experiment, in percentage

\begin{tabular}{|l|l|l|l|}
\hline \multirow{2}{*}{ number of students } & $\begin{array}{l}2016-2017 \\
\text { (the 10th grade) }\end{array}$ & $\begin{array}{l}\text { 2017-2018 } \\
\text { (the 11th } \\
\text { grade) }\end{array}$ & mark \\
\hline \multirow{2}{*}{68} & $30.9 \%(21)$ & $47 \%(32)$ & "4" and "5" \\
\cline { 2 - 4 } & $69.1 \%(47)$ & $53 \%(36)$ & positive grades \\
\hline
\end{tabular}

The table shows that an additional 11 students wrote a quality control assessment, which corresponds to an increase of about $16 \%$ from the initial indicator.

The results of the assessments allowed for concluding that the use of tasks in mathematics lessons is effective, the plot of which contains social, cognitive, practical, historical, regional, vocational, and interdisciplinary significance; the use of various modern pedagogical technologies in the lessons of mathematics.

\section{Discussion}

Reasonable pedagogical conditions contribute to the development of cognitive independence of students in humanitarian classes and the manifestation of activity in the study of mathematics.

The experiment consisted of three stages: ascertaining, forming, and control stages. The first stage involved a survey of teachers to identify which textbooks teach are used in teaching mathematics; conversation with students 
to identify a motivation, interest in the study of mathematics; primary diagnostics of the level of training in mathematics at a basic level; logical and didactic analysis of textbooks in mathematics. The second stage involved the creation of pedagogical conditions (the compilation and use of a training package in mathematics that meets the needs and capabilities of students in the humanities), the use of active, personality-oriented, informationcommunicative and competency-based approaches, modern methods, technologies and tools that are aimed at developing cognitive independence in learning mathematics. The third stage involved the control diagnostics of the training level in mathematics and the analysis of results.

The main types of work that the authors used to develop the cognitive independence of students in mathematics classes included: solving problems with regional content; solving historical, practical, cognitive tasks; conducting integrated lessons; use of modern educational technologies; reflection, and use of differentiated tasks.

Four assessments were carried out to determine the level of advanced training in mathematics, an indicator of the development of cognitive independence in the study of mathematics.

It is notable that in school education for the development of cognitive independence of students, attention should be paid to the professional growth and personal development of the teacher. The professional skill of the teacher, his example and personal qualities help students learn, imitate, and develop.

\section{Conclusion}

The development of the cognitive independence of students in humanitarian classes in the study of mathematics is most effective if:

- Pedagogical conditions are used that consider the possibilities and desires of students;

Age, individual characteristics, and personal qualities of students are considered;

Activity-oriented, personality-oriented, informationcommunicative, and competency-based approaches are employed extensively.

The educational material, properly selected per the goals, teaching 
methods and forms of organization of the educational process, contribute to the formation of basic knowledge; the search for a rational approach in solving the problem; systematization of acquired knowledge; the development of logical thinking; conducting simple experiments and research; conscious determination of the future profession.

\section{References}

Amy Roth McDuffie, Jeffrey Choppin, Corey Drake, Jon Davis. Middle school mathematics teachers' orientations and noticing of features of mathematics curriculum materials. International Journal of Educational Research, In press, corrected proof, Available online 8 October 2018.

Avgustina Vasilievna Ivanova; Valentina Nikolaevna Everstova; Aya Petrovna Bugaeva; Alevtina Gavrilovna Scriabina; Natalia Anatolievna Ivanova Pedagogical conditions for supporting the personal self-development of a fifthgrade pupil in the process of mathematical education. 2018 / Revista ESPACIOS. Vol. 39 (\#23). Year 2018.Page 18.
Barakhasanova E.A., Vlasova E.Z, Golikov A.I., Kuzin Z.S., Prokopyev M.S., Burnachov A.E. Peculiarities of quality management of teachers elearning training in the Arctic regions. EDUCATION, 2018. 38(55), 25

Barakhasanov V.P., Barakhasanjva E.A., Olesov N.P., Prokopyev M.S. E-learning system application for physical education and sports specialist training. Theory and Practice of Physical Culture. 2018. 7. C.4

Carolyn A. Maher, Robert Sigley, Peter Sullivan, Louise C. Wilkinson. An international perspective on knowledge in teaching mathematics. The Journal of Mathematical Behavior, Volume 51, September 2018, Pages 71-79.

Doug Clarke, Anne Roche. Using contextualized tasks to engage students in meaningful and worthwhile mathematics learning The Journal of Mathematical Behavior, Volume 51, September 2018, Pages 95-108.

Elena

Koshkina, Nina

Bordovskaia, Natalia

Bochkina. 
Didactic Terminology Operated by Russian Future and Practicing Teachers: Comparative Analysis. Procedia - Social and Behavioral Sciences, Volume 217, 5 February 2016, Pages 42-48.

Fou-Lai Lin, Ting-Ying Wang, Kai-Lin Yang. Description and evaluation of a $\underline{\text { large-scale project to facilitate student }}$ engagement in learning mathematics Studies in Educational Evaluation, Volume 58, September 2018, Pages 178186.

Vlasova E.Z., Barakhasanjva E.A., Goncharova S., Aksyutin P., Kuzin Z.S., Prokopyev M.S. Effective adaptive training of the student in Russian pedagogical universities to use elearning technologies. EDUCATION, 2018. 39(23), 10

Jozef Simuth, Ivan SarmanySchuller.The Preferences of Cognitive Style Among University Students From Various Study Fields. Procedia - Social and Behavioral Sciences, Volume 191, 2 June 2015, Pages 2537-2540.

$\begin{array}{lr}\text { Katherine } \quad \text { B. } & \text { Owen, Philip D. } \\ \text { Parker, Thomas } & \text { Astell-Burt, Chris }\end{array}$
Lonsdale. Effects of physical activity and breaks on mathematics engagement in adolescents. Journal of Science and Medicine in Sport, Volume 21, Issue 1, January 2018, Pages 63-68.

Lidiya Kazarina, Yuri

Khasanshin, Larisa Smyshlyaeva. Teaching Model of Pupils' Research Competence Formation in the Context of Humanitarian Subject-oriented Classes of General Education School: Functional and Organizational Characteristics. Procedia - Social and Behavioral Sciences, Volume 206, 17 October 2015, Pages 241-246.

Linor L. Hadar. Mathematics textbooks and students, achievements Studies in Educational Evaluation, Volume 55, December 2017, Pages 153-166.

Maskura G. Balabekova, Melis K. Asanaliev, Gulnaz

A.

Ospanova, Zhadyra A. Kudabaeva. Methodical Peculiarities of Development of students Cognitive Independency. Procedia - Social and Behavioral Sciences, Volume 89, 10 October 2013, Pages 812-816. 
Nikolai Dmitrievich Neustroev, Alla

Dmitrievna Nikolaeva, Anna

Nikolaevna Neustroeva, Avgustina

Vasilievna Ivanova. Problems and

Modernization Trends of Ungraded

Schools of the Russian North Jejme Mathemetics education. 2016, vol. 11,NO. 3415-3424.

Avanesov, V.S. Modernization of education in Russia: the key problems and solutions. Public education. - 2017.No. 1 (2). - Pp.20-32.

Barakhsanova E.A., Mulgarov I.I. Schoolchildren in a digital educational environment: conditions, preferences, and security. Problems of modern teacher education. 2018. No. 61-2. Pp. 64-66

Bespalko, V.P. The quality of education and the quality of training. Public education. - 2017. - No. 3-4. Pp. 105114.

Gafurova, N.V., Osipova S.I. Ideas and problems of advanced education. Siberian pedagogical journal. - 2013 No. 4. - Pp. 9-14.
Ziyautdinova, S.M., Ziyautdinov, M.D., Rajabaliev, G.P. The didactic potential of electronic educational resources in the organization of students' independent work. The world of science, culture, education. - 2015. - No. 6 (55). - Pp. 4547.

Ivanova, A.V., Skryabina, A.G., Stepanova, L.V. Levels and indicators of the formation of independent cognitive activity of students in humanities. Modern problems of science and education. -2018. - No. 4; - Access mode: http://www.scienceeducation.ru/article/view?id=27743 (Ac cess date: 12.07.2018).

Isakhanova, Z.S. Technologies of a personality-oriented approach in education. Questions of pedagogy. 2017.- No. 6. - Pp. 31-32.

Istratova, O.N., Exacusto, T.V. Reference psychologist of high school. 6th ed. - Rostov-on-Don: Phoenix, 2010 .-- 510 p.

Klepikov, V.N. Psychological barriers to the study of mathematics in a modern 
school. Pedagogy. - 2017.- No. 6. - Pp. 33-39.

Krasnova, L.A. The principle of selection of the content of general education. The Pedagogical Journal of Bashkortostan - 2016 - No. 6. - Pp. 5154.

Laptev, V.V., Noskova, T.N. Pedagogical activity in the electronic environment: prospects of a new quality. Pedagogy .- 2016. - No. 10. - Pp. 3-13.

Markova, A.K. Formation of motivation for learning at school age: a manual for the teacher. - Access mode: http://shag.com.ua/markova-a-kformirovanie-motivacii-ucheniya-vshkolenom-vozras.html.

Osipova, S.I., Bratukhina, N.A., Bugaeva, T.P., Klimovich, L.V. The development of cognitive competence of future bachelors in the process of teaching mathematics. The Pedagogic Journal. - 2017. - Vol. 7, No. 5A. - Pp. 100-107.

Petunin, O.V. Implementation of a system-activity approach in a modern school lesson. Society: sociology, psychology, pedagogy. - 2016, No. 8. Pp. 62-64.

Prokopyeva, M.M., Abramova, N.N. Cooperation of different ages as a condition for the formation of metasubject competencies of students. Scientific and methodological journal "Concept". - 2017. - Vol. 6. - Pp. 46-49.

Pustovoitov, V.N. Cognitive independence is the key competence and competence of the individual. Bulletin of the Pyatigorsk State Linguistic University. - 2010 .-- Pp. 290-294.

Rakhmatullina, A.O., Krutikhina, M.V. Factors affecting the selection and content of educational material in mathematics in humanitarian classes. Scientific and methodological electronic journal "Concept". - 2015. - Vol. 6. - Pp. 26-30. - URL: http://ekoncept.ru/2015/65206.htm.

Rohaeti, E.E. (2019). Building Students' Hard and Soft Skills through Innovative Teaching Approaches to Mathematics. Journal of Southwest Jiaotong University, 54(5). 
http://jsju.org/index.php/journal/article/ view/366

Sedova, E.A. In search of motivation to study mathematics. Mathematics in the school. - 2015. - No. 4. - Pp. 63-66.

Fetiskin, N.P., Kozlov, V.V., Manuylov, G.M. Socio-psychological diagnosis of the development of personality and small groups. Moscow: Publishing house of the Institute of Psychotherapy, 2002. $490 \mathrm{p}$.

Yafizova, R.A., Koshevarova, Yu.A., Nikolaev, A.D., Zhdanov, E.R., Lyubarchuk, F.N. Implementation of interactive teaching methods in the context of Federal State Education Standards. Global scientific potential. 2016. - No. 5 (62). - Pp. 29-31 